\title{
Correction to: Mathematical Theory of Evolutionary Fluid-Flow Structure Interactions
}

Barbara Kaltenbacher, Igor Kukavica, Irena Lasiecka, Roberto Triggiani, Amjad Tuffaha, and Justin T. Webster

\section{Correction to:}

B. Kaltenbacher et al., Mathematical Theory of Evolutionary Fluid-Flow Structure Interactions, https://doi.org/10.1007/978-3-319-92783-1

The book was inadvertently published with an incorrect author affiliation for Justin T. Webster "University of Maryland, College Park, Maryland, MD, USA" where as it should be "University of Maryland Baltimore County, Baltimore, MD, USA".

The updated online version of this book can be found at https://doi.org/10.1007/978-3-319-92783-1 